\title{
CORRECTION
}

\section{THE FATE OF PREMATURE BABIES IN WARWICKSHIRE}

Dr. C. Fraser Brockington has written to apologize for certain errors in the figures given in the table on p. 94 of his contribution in the June issue under the above title. The correct version of the table is as follows:-

PREMATURE BIRTHS IN WARWICKSHIRE, 1943

Total births . 8650

No. premature .. 329

Percentage premature $\quad . \quad 3 \cdot 8$

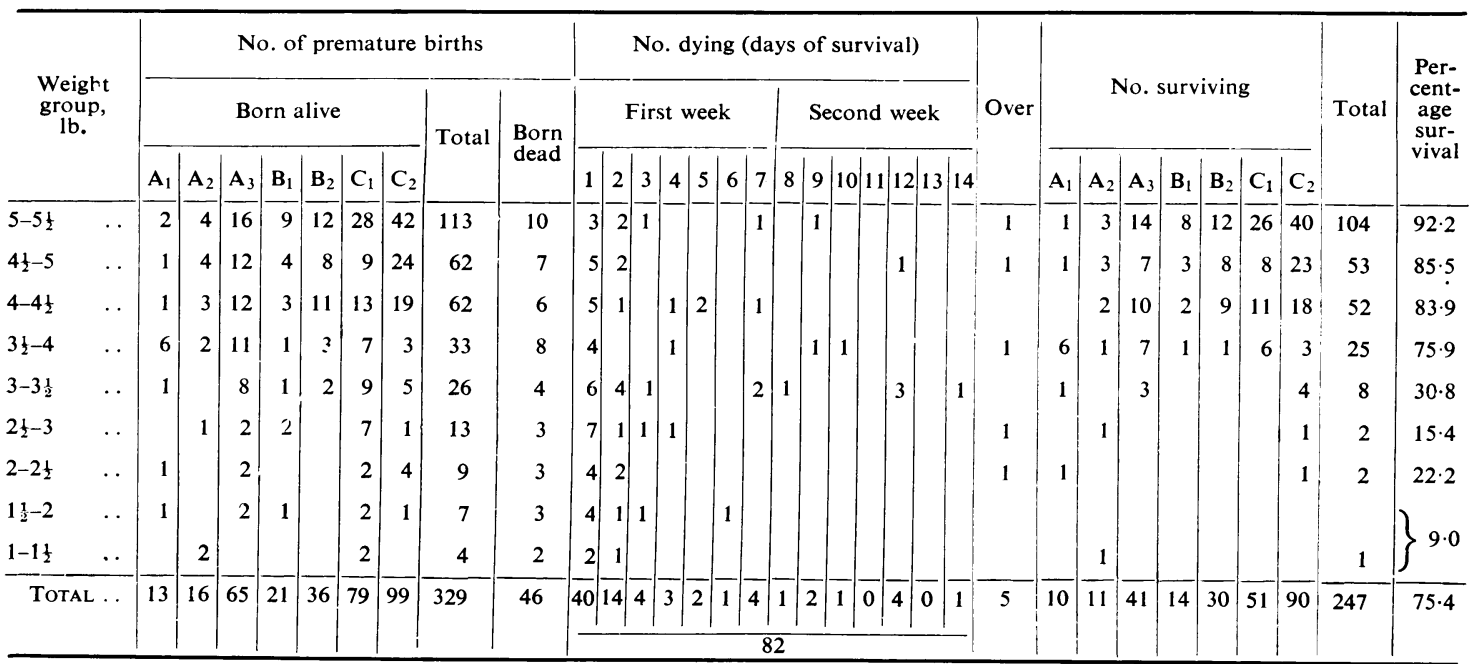

$A_{1}$ Attended by an independent midwife.

$A_{2}$ Attended by a county council midwife.

$\mathrm{A}_{3}$ Attended by a district nursing association midwife.

$B_{1}$ Born in a nursing home. $B_{2}$ Born in a maternity home.
$\mathrm{C}_{1}$ Born in a municipal hospital. $\mathrm{C}_{2}$ Born in a voluntary hospital.
He sends the following comments:-

The figure for the municipal hospitals has been altered; total of premature babies reading 79 in place of 61 ; with 51 surviving instead of 39 . The survival rate is 65 instead of 64 (D-C in the script $=25 \pm 6 \cdot 1$ ).

This makes no difference to the inferences to be drawn, but it causes a number of minor alterations in the table and the script:-

1. The numbers and times of those dying are changed:

82 died, 54 in the first 48 hours, i.e. 67 per cent., and 83 per cent. in the first week.
Of those over $3 \frac{1}{2} \mathrm{lb} .22$ out of 36 (60 per cent.) died in the first 48 hours.

Of those under $3 \frac{1}{2} \mathrm{lb}$. 32 out of 46 (70 per cent.) died in the first 48 hours.

The percentage dying in the first 48 hours is thus not 'higher' in the over $3 \frac{1}{2}$ pounders as stated in the script, but ' nearly as high.'

2. The percentage survivals are altered throughout, but not appreciably. Also one baby survived under $2 \mathrm{lb}$. out of 16 instead of 15 .

3. The number of prematures reads 329 and the percentage of prematures is raised from 3.6 to 3.8 . 